\title{
Modification, Synthesis, and Analysis of Advanced Materials Using Ion Beam Techniques
}

\author{
Adam Georg Balogh, ${ }^{1}$ Koumei Baba, ${ }^{2}$ David D. Cohen, ${ }^{3}$ Robert G. Elliman, ${ }^{4}$ \\ Wolfgang Ensinger, ${ }^{1}$ and Joseph Gyulai ${ }^{5}$ \\ ${ }^{1}$ Institute of Materials Science, Technische Universität Darmstadt, 64287 Darmstadt, Germany \\ ${ }^{2}$ Industrial Technology Center of Nagasaki, Omura 8560026, Japan \\ ${ }^{3}$ Australian National Science and Technology Organisation, Kirrawee DC, NSW 2232, Australia \\ ${ }^{4}$ Department of Electronic Materials Engineering, Research School of Physics and Engineering, Australian National University, \\ Canberra, ACT 0200, Australia \\ ${ }^{5}$ Research Institute for Technical Physics and Materials Science, Hungarian Academy of Sciences, 1121 Budapest, Hungary
}

Correspondence should be addressed to Adam Georg Balogh, agbalogh@nano.tu-darmstadt.de

Received 23 October 2011; Accepted 23 October 2011

Copyright (C) 2012 Adam Georg Balogh et al. This is an open access article distributed under the Creative Commons Attribution License, which permits unrestricted use, distribution, and reproduction in any medium, provided the original work is properly cited.

Energetic ion beams are employed for the synthesis, modification, and analysis of advanced, technologically important materials, and many novel applications have emerged over the past several decades. The evolution of the field over this period is recorded in a broad range of conferences that are dedicated to particular aspects of ion-beam modification or analysis of materials, including international conferences on ion beam modification of materials (IBMM), ion beam analysis (IBA), surface modification of materials by ion beams (SMMIB), and so forth. This special issue aims to present some of the latest results in the field.

The special issue contains five review papers covering areas of particular current significance, and nine topical research papers. The review paper by J. C. McCallum et al. presents an overview of single-ion implantation for deterministic doping of semiconductors, with a particular focus on quantum computing and communication. The paper by $\mathrm{L}$. Thome et al. summarizes the current understanding of radiation effects in nuclear ceramics, a topic of direct relevance to the immobilization of radioactive waste and the choice of structural materials for fusion reactors. The paper by K. Grandfield and H. Engqvist reviews the application of focused ion beams (FIBs) in life science, reporting the advances and challenges of FIB techniques in the life sciences, including TEM preparation techniques. The paper by S. P. Dash et al. is dealing with interface and interdiffusion effects in Co/Si systems using a special high-resolution Rutherford backscattering spectrometer (HRBS). The authors also demonstrate that the $\mathrm{Co} / \mathrm{Si}$ interdiffusion can be stopped using a thin $\mathrm{MgO}$ diffusion barrier layer. The paper by $\mathrm{K}$. Zakrzewska summarizes the properties and defect structure of nonstoichiometric $\mathrm{TiO}_{2}$ thin films using different ion beam methods.

The topical research papers serve to highlight the diversity and flexibility of ion beam modification and analysis techniques and cover a broad range of material systems and analytical approaches.

The paper of J. Arunkumar et al. addresses the analysis of minor alloying elements in structural reactor materials. The contribution from $\mathrm{Z}$. Li et al. presents the different irradiation properties of nuclear graphite materials with respect to porosity, pore size, and morphology before and after irradiation.

The contribution from Drogowska et al. studies the effect and distribution of hydrogen in $\mathrm{Ti} / \mathrm{Si}, \mathrm{Ti} / \mathrm{TiO}_{2} / \mathrm{Si}$, and $\mathrm{Pd} / \mathrm{Ti} / \mathrm{TiO}_{2} / \mathrm{Si}$ thin-film systems verifying the higher $\mathrm{H}$ in-diffusion for systems with Pd top layer. The contribution from H. A. Shukur et al. addresses the morphology, structure, and optical characteristics of irradiated $\mathrm{TiO}_{2}$ films, demonstrating improved photocatalytic activity of $\mathrm{TiO}_{2}$ after $\mathrm{N}^{+}$irradiation due to the replacement of $\mathrm{O}$ atoms by $\mathrm{N}$ atoms. 
The paper from L. Meissner et al. reports the biocompatibility of NiTi specimens after high-dose $\mathrm{Si}, \mathrm{Ti}$, and $\mathrm{Zr}$ implantation revealing the nontoxicity of these materials and associated mesenchymal stem cells (MCS) proliferation.

There are two articles that deal with implantation effects. The first one from K. Baba et al. addresses the doping effects of silver on the structure and properties of diamondlike carbon (DLC), demonstrating improved tribological properties after silver implantation. The second one from $\mathrm{R}$. Machaka et al. presents a systematic study on implantation effects on the mechanical and structural properties in the near-surface region of boron suboxide $\left(\mathrm{B}_{6} \mathrm{O}\right)$.

Other two papers of this special issue are concerned with technique development and improvement. The first one from J. A. Whitby et al. combines a special time-of-flight secondary ion mass spectrometer (SIMS) with focused ion beam (FIB) and scanning electron microscopy (SEM) to provide information about the roughness of surfaces, and to provide three-dimensional chemical images with a resolution below $50 \mathrm{~nm}$. The contribution from V. Haeublein et al. addresses the issue of ion beam transport and its effect on beam purity and sample contamination using a newly developed simulation tool for modelling the transport mechanisms of ions in the magnet analyser.

\author{
Adam Georg Balogh \\ Koumei Baba \\ David D. Cohen \\ Robert G. Elliman \\ Wolfgang Ensinger \\ Joseph Gyulai
}



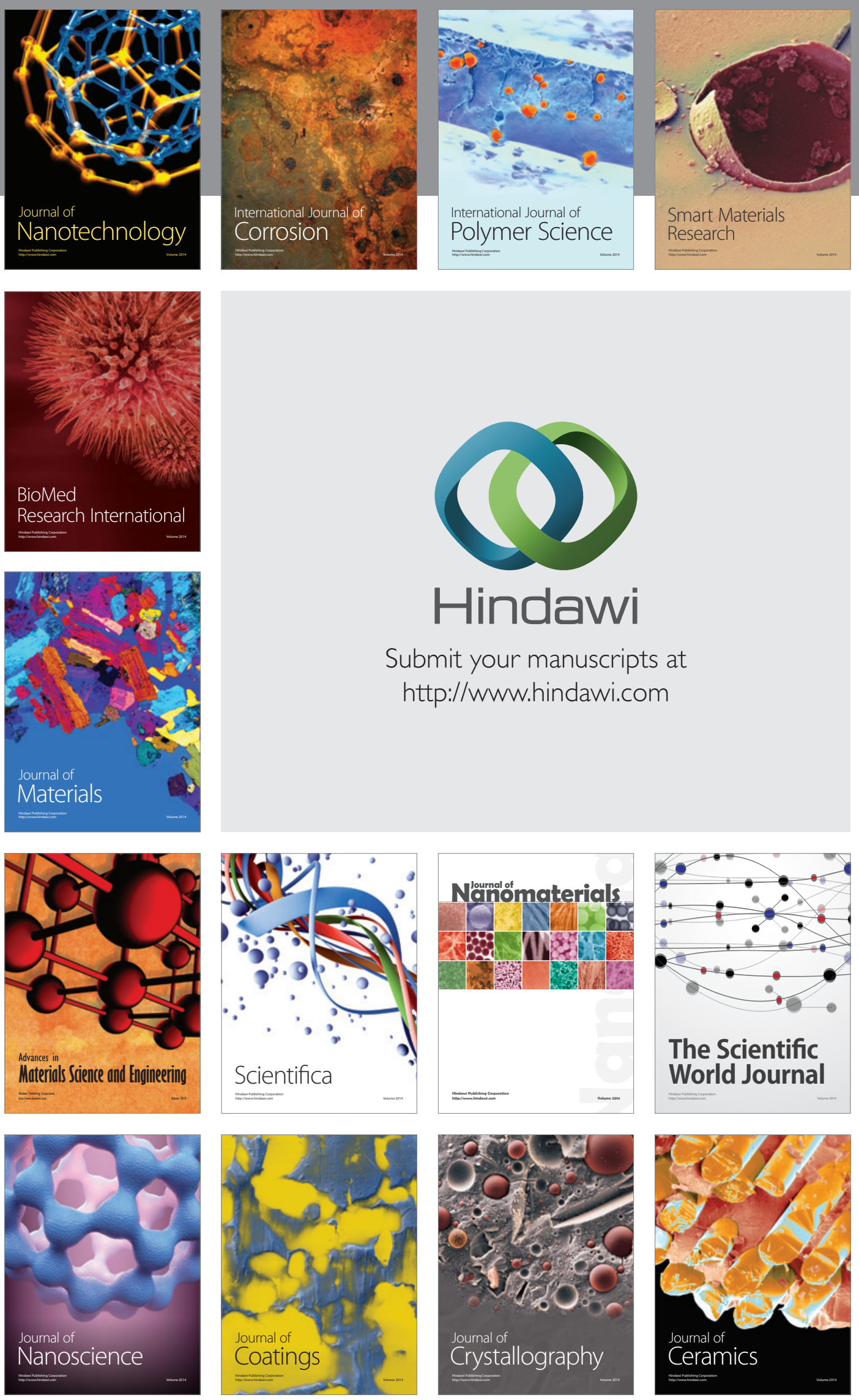

The Scientific World Journal

Submit your manuscripts at

http://www.hindawi.com

\section{World Journal}

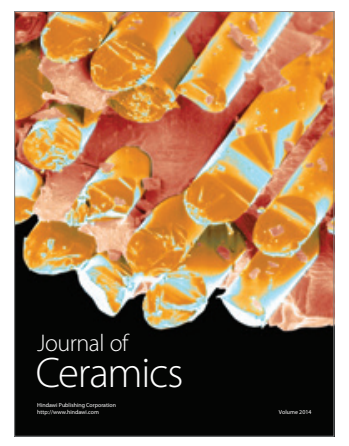

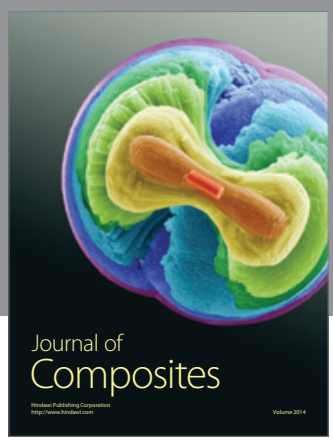
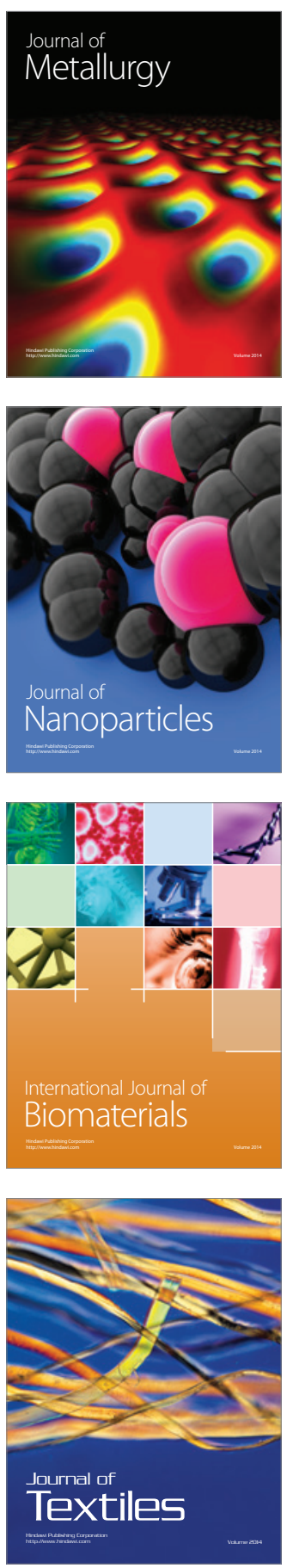